Brazilian Journal

of Chemical

ISSN 0104-6632

Printed in Brazil

Engineering

www.scielo.br/bjce

Vol. 35, No. 02, pp. 327 - 340, April - June, 2018

dx.doi.org/10.1590/0104-6632.20180352s20160265

(cc) BY

\title{
OPTIMIZATION OF THE EXTRACTION OF FREE FATTY ACIDS APPLIED TO BIODIESEL PRODUCTION\#
}

\author{
Allan A. Albuquerque ${ }^{1}$, Cláudia J. S. Cavalcanti ${ }^{1}$, Cícero H. M. Soares ${ }^{1}$, \\ Maria Fernanda Pimentel ${ }^{1}$ and Luiz Stragevitch ${ }^{1, *}$
}

Fuel Laboratory, Chemical Engineering Department, Federal University of

Pernambuco, Av. Prof. Artur de Sá S/N, CEP 50740-521, Recife, PE, Brazil.

(Submitted: April 26, 2016; Revised: October 8, 2016; Accepted: January 20, 2017)

\begin{abstract}
The liquid-liquid extraction of free fatty acids (FFA) from residual oils and fats for biodiesel production, employing methanol as the solvent, has been optimized using process simulation and response surface methodology. The parameters investigated were temperature, number of stages and solvent-to-feed ratio $(S / F)$. Responses evaluated were FFA mass fraction in the oil-rich phase $\left(w_{\mathrm{FFA}}^{\mathrm{B}}\right)$ and total cost, using yellow and brown greases as the raw materials. Quadratic and linear models were fitted for $w_{\mathrm{FFA}}^{\mathrm{B}}$ and cost responses, respectively. The optimal conditions satisfying technical $\left(w_{\mathrm{FFA}}^{\mathrm{B}} \leq 0.5 \%\right)$ and economic (minimum cost, including capital and operation costs, except for raw material cost) criteria were $321 \mathrm{~K}, 6$ stages, $S / F=1.27, w_{\mathrm{FFA}}^{\mathrm{B}}=0.41 \%$, cost $=$ $\$ 84.93 /$ ton (yellow grease), and $318 \mathrm{~K}, 6$ stages, $S / F=1.32, w_{\mathrm{FFA}}^{\mathrm{B}}=0.49 \%$, cost $=\$ 102.89 /$ ton (brown grease).
\end{abstract}

Keywords: Biodiesel, Residual oils and fats, Free fatty acids, Liquid-liquid extraction, Response surface methodology.

\section{INTRODUCTION}

Biodiesel production is usually carried out through a transesterification reaction, which consists of a chemical reaction of a vegetable oil, animal fat or residual oil and fat (ROF) with a short chain alcohol (methanol or ethanol) in the presence of a catalyst (Van Gerpen, 2005; Gnanaprakasam et al., 2013). Refined vegetable oils are largely employed as raw materials in the biodiesel industry; they can represent up to $85 \%$ of biodiesel costs. Thus, less costly raw materials, such as ROF, have been gaining more attention (Canakci and Sanli, 2008; Avhad and Marchetti, 2015).

ROF can be $40 \%$ to $70 \%$ cheaper than refined vegetable oils (Refaat, 2010; Cai et al., 2015).
In addition, environmental and economic issues related to the improper disposal of ROF are a concern. Further, sewage treatment plants are subjected to increasing costs to treat ROF (Iasmin et al., 2014; Ortner et al., 2016). Among ROFs, waste frying oils are derived from various vegetable oils, such as sunflower, corn, and especially soybean oil (Jorge et al., 2005; Tsoutsos et al., 2016). ROFs such as from waste frying oils and animal fat wastes have high levels of free fatty acids (FFA) (Gnanaprakasam et al., 2013). ROFs can be generally found as yellow or brown greases depending on whether the FFA content is between $5 \%$ and $15 \%$ (yellow) or above $15 \%$ (brown) (Canakci and Sanli, 2008; Adewale et al., 2015; Avhad and Marchetti, 2015).

\footnotetext{
* Corresponding author: Luiz Stragevitch. E-mail: luiz@ufpe.br.

" This is an extended version of the manuscript presented at the VIII Brazilian Congress of Applied Thermodynamics - CBTermo 2015, Aracaju, Brazil.
} 
High FFA levels in the raw material cause operational drawbacks in the achievement of high biodiesel yields, mainly due to the occurrence of competitive reactions of FFA saponification and triacylglycerol (TAG) hydrolysis (Gnanaprakasam et al., 2013). To increase the production yield, ROF is usually subjected to an initial pretreatment step with an acid-catalyzed esterification reaction; then, the resulting stream undergoes an alkali-catalyzed transesterification step (Canakci and Van Gerpen, 2001), which is known as the conventional process. The acidcatalyzed pretreatment step increases capital and operation costs since it requires additional equipment and a glycerol washing stage (Zhang et al., 2003).

On the other hand, alternative processes employing the FFA separation from the oil have proven to be economically more attractive (Albuquerque et al., 2016). FFA separation is widely used in the food industry to produce edible oils. FFA separation can be carried out by liquid-liquid extraction (LLEx) using a short-chain alcohol as the solvent (Bhosle and Subramanian, 2005; Rodrigues et al., 2007; Vaisali et al., 2015), making it a potentially interesting process for the biodiesel industry. Despite this, studies using LLEx to separate FFA, including cost estimates, have not been found in the literature, except in the refining of edible oils with ethanol and ethanol/water mixtures as solvents (Batista et al., 1999b; Pina and Meirelles, 2000; Batista et al., 2002). Because the biodiesel industry predominantly uses methanol as the reaction agent, development of a LLEx process to separate FFA with methanol as the solvent may be of interest to the industry.

In this work, the LLEx of FFA from ROF employing methanol as the solvent was optimized using response surface methodology (RSM) and Aspen software for process simulation. The parameters investigated were temperature $(T)$, number of stages $(N)$ and solvent to feed ratio $(S / F)$. The FFA mass fraction (solvent free basis) in the oil-rich phase $\left(w_{\mathrm{FFA}}^{\mathrm{B}}\right)$ and the total cost were the responses evaluated. The study goals were: to attain $w_{\text {FFA }}^{\mathrm{B}}$ values below the recommended FFA concentration in TAG (a mass fraction of $0.5 \%$ ) for the alkali-catalyzed transesterification step (Ma and Hanna, 1999); and to attain technical and economic feasibility of the process with a minimum total cost.

\section{METHODOLOGY}

\section{Thermophysical properties prediction and thermodynamic modeling}

Thermophysical properties for the ROF were predicted using the Constituent Fragments (CF) and
Extended Constituent Fragments (ECF) approaches (Zong et al., 2009; Cruz-Forero et al., 2012). Subsequently, a rigorous thermodynamic modeling applied to vegetable oil/FFA/methanol systems was carried out to represent the liquid-liquid equilibrium (LLE) in the LLEx column. The NonRandom Two-Liquid (NRTL) model was used (Renon and Prausnitz, 1968).

Experimental LLE data from Batista et al. (1999a), Mohsen-Nia and Dargahi (2007), Liu et al. (2008) and Mohsen-Nia and Khodayari (2008) were used to estimate the NRTL binary interaction parameters to be used in the process simulation. The NRTL parameters were estimated by minimization of the objective function given by (Stragevitch and d'Ávila, 1997)

$$
F=\sum_{i=1}^{N_{c, k}} \sum_{j=1}^{N_{t, k}} \sum_{k=1}^{N_{D}} \sum_{l=1}^{2}\left(w_{i j k}^{(l), \text { exp }}-w_{i j k}^{(l, \text { cal }}\right)^{2}
$$

where $w$ is the phase composition (mass fraction); exp and cal denote experimental and calculated compositions, respectively; $N_{c, k}$ and $N_{t, k}$ are, respectively, the number of components and tie lines in the $k$-th data set; $N_{\mathrm{D}}$ is the number of data sets simultaneously correlated; subscripts $i, j$ and $k$ denote components, tie lines and data sets, respectively; and superscript $l$ denotes phases in equilibrium . Experimental and calculated compositions involved in LLE systems were compared using the root mean square deviation (RMSD), according to

$$
\Delta w=100 \times \sqrt{\frac{1}{2 N_{t} N_{c}} \sum_{i=1}^{N_{c}} \sum_{j=1}^{N_{l}} \sum_{l=1}^{2}\left(w_{i j}^{(l), \text { exp }}-w_{i j}^{(l), \text { cal }}\right)^{2}}
$$

for each data set as well as a global deviation involving all correlated data sets.

\section{Process simulation}

Aspen software was used in the process simulation. The ROF composition used in the LLEx column was defined based on a mixture of the vegetable oils found in the vegetable oil/FFA/methanol LLE systems available (Batista et al., 1999a; Mohsen-Nia and Dargahi, 2007; Liu et al., 2008; Mohsen-Nia and Khodayari, 2008). Figure 1 illustrates the LLEx column, which was operated at constant pressure $(101.3 \mathrm{kPa})$ and was fed at the top stage with $1050 \mathrm{~kg} / \mathrm{h}$ of ROF, while the methanol (M) (solvent) was fed at the bottom stage. Two cases were studied to evaluate the FFA/ROF separation from a wide range of FFA content. For 
case 1 , a ROF composed of $10 \%$ FFA was adopted; while for case 2 , a ROF with $20 \%$ of FFA was used. In both cases the remaining content was the TAG. Cases 1 and 2 are representative of common ROFs found, known as yellow and brown greases, respectively (Canakci and Sanli, 2008; Mohite et al., 2015).

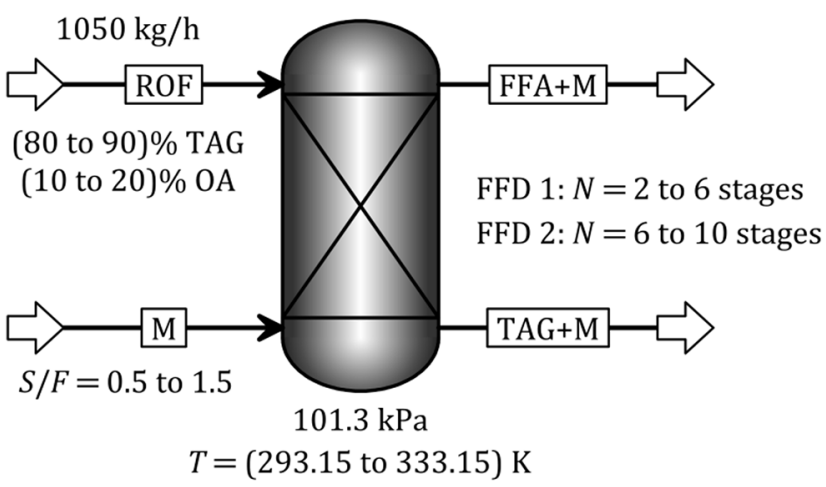

Figure 1. Flowsheet of FFA separation from ROF using a LLEx column.

\section{Full Factorial Design and Response Surface Methodology}

In order to optimize the FFA separation from ROF using a LLEx process, initially a $2^{3}$ full factorial design (FFD) including a central point was carried out. The parameters investigated were $T, N$ and $S / F$ as presented in Table 1 and in Figure 1, where FFD 1 (design 1) and FFD 2 (design 2) differ only in the levels used for $N$. The levels for $N$ and $S / F$ were chosen based on the process simulation of an alternative process to produce biodiesel applying FFA separation from ROF by LLEx (Albuquerque et al., 2016) while temperature levels were defined by the temperature range from the available LLE data.

The FFA mass fraction (solvent free basis) in the oil-rich phase $\left(w_{\mathrm{FFA}}^{\mathrm{B}}\right)$, found at the bottom output stream of the extraction column, and the total cost involved in the first year of the LLEx column operation, were the responses evaluated. The goal was to achieve the design and operational conditions that simultaneously satisfied the recommended specification of $w_{\text {FFA }}^{\mathrm{B}}$ $\leq 0.5 \%$ and minimum total cost in the first year of operation. The latter took into account capital and operation costs.
Capital costs included the LLEx column and heaters or coolers (purchase cost) adopting the preliminary Chemical Engineering's Plant Cost Index (CEPCI) of 537.7 (December, 2015). In this study, the LLEx column was designed as a rotating disk contactor (RDC). The RDC type was chosen following selection schemes for extractors based on heuristics from commercial extractors (Seader et al., 2011). The extractor diameter and height were calculated based on Seider et al. (2009) and Seader et al. (2011). Following Seider et al. (2009), the heat exchangers were designed as a double-tube type (area less than $150 \mathrm{ft}^{2}$ ) or shell and tube type (area greater than $150 \mathrm{ft}^{2}$ ). A detailed description of the design procedure can be found in Albuquerque et al. (2016).

Operation costs included utility costs (vapor or water in heat exchangers) and solvent (methanol) cost and were calculated as presented by Albuquerque et al. (2016). The methanol cost was calculated multiplying the price of methanol $(\$ 0.85 / \mathrm{kg})$ by the methanol mass flow rate fed plus a factor to account for the solvent make-up, $7.4 \%$ and $8.5 \%$ for cases 1 and 2 , respectively (Albuquerque et al., 2016). The raw material (ROF) cost was not included in the operation costs to avoid masking since it is significantly higher than the capital and other operation costs. Nonetheless, it is constant for a constant flow rate of ROF, as used in this work, thus, not affecting the conclusions obtained.

After the results of the $2^{3}$ design were evaluated, new computational experiments, using a central composite design (CCD), were carried out to estimate the coefficients of a quadratic model. Statistica Ultimate Academic software was employed in all calculations.

\section{RESULTS AND DISCUSSION}

\section{Thermophysical properties prediction and thermodynamic modeling}

Trilinolein (LLL) was adopted as the representative TAG of ROF in the process simulations. LLL was chosen based on the FFA compositions of the vegetable oils found in the oil/FFA/methanol LLE systems used, which indicated linoleic acid as the

Table 1. Factors and levels of factorial design.

\begin{tabular}{|c|c|c|c|c|c|c|}
\hline & \multicolumn{3}{|c|}{ FFD 1 (design 1) } & \multicolumn{3}{|c|}{ FFD 2 (design 2) } \\
\hline & \multicolumn{3}{|c|}{ Level } & \multicolumn{3}{|c|}{ Level } \\
\hline Factor & - & 0 & + & - & 0 & + \\
\hline Temperature, $T(\mathrm{~K})$ & 293.15 & 313.15 & 333.15 & 293.15 & 313.15 & 333.15 \\
\hline Number of stages, $N$ & 2 & 4 & 6 & 6 & 8 & 10 \\
\hline Methanol to oil mass ratio, $S / F$ & 0.5 & 1 & 1.5 & 0.5 & 1 & 1.5 \\
\hline
\end{tabular}


most abundant fragment (Batista et al., 1999a; Mohsen-Nia and Dargahi, 2007; Liu et al., 2008; Mohsen-Nia and Khodayari, 2008). Furthermore, LLL was also the most important TAG composed of homogenous fragments. Use of a TAG composed of only one carbon chain simplifies the transesterification reaction modeling since only one diacylglycerol and one monoacylglycerol need to be used. The TAG composition of the ROF used is shown in Table 2, and was calculated from the FFA composition of a mixture of canola, corn, sunflower and jatropha curcas oils present in the LLE data adopted. The methodology proposed by Antoniosi Filho et al. (1995) was used. Only the main FFAs (palmitic $11.7 \%$, stearic $3.2 \%$, oleic $33.3 \%$, linoleic $48.3 \%$ and linolenic $3.5 \% \mathrm{wt}$ ) were used to calculate the TAG composition, since they represented $98.7 \%$ of the FFA composition of canola oil, $98.2 \%$ of corn oil, $99.7 \%$ sunflower oil and $99.4 \%$ of jatropha curcas oil.

A number of thermophysical properties were predicted for the ROF, for example: enthalpy of vaporization at $298.15 \mathrm{~K}(166 \mathrm{~kJ} / \mathrm{mol})$, vapor pressure, liquid heat capacity, mass density and viscosity. Mass density and viscosity were estimated by the CF method, while the others were estimated by the ECF method.
The results were compared to several vegetable oils for which the properties measured are reported in the literature, as shown in Figure 2 (Perry et al., 1949; Noureddini et al., 1992; Morad et al., 2000; Ceriani et al., 2008). Differences were encountered since the oils are different; Figure 2 shows that the predicted values for the ROF used, however, were consistent with common oils.

LLE data reported in the literature were employed to carry out the thermodynamic modeling. The systems used were: canola oil (CnO)/oleic acid (OA)/methanol (M) at $293.15 \mathrm{~K}$ and $303.15 \mathrm{~K}$ (Batista et al., 1999a); jatropha curcas oil (JO)/OA/M at 303.1, 313.1, 323.1 and 333.1 K (Liu et al., 2008); corn oil (CO)/OA/M at $303.15 \mathrm{~K}$ and $313.15 \mathrm{~K}$ (Mohsen-Nia and Dargahi, 2007) and sunflower oil (SuO)/OA/M at $303.15 \mathrm{~K}$ and 313.15 K (Mohsen-Nia and Khodayari, 2008). Table 3 shows the RMSD obtained using the NRTL model. Agreement between experimental and calculated LLE was satisfactory to develop a reliable simulation of the extraction process. A comparison of experimental and calculated LLE data using the NRTL model is shown in Figure 3 for some selected systems (one system for each oil at different temperatures). The NRTL interaction parameters obtained are shown in Table 4.

Table 2. TAG composition of the ROF used.

\begin{tabular}{|c|c|c|c|}
\hline TAG name & & & \\
\hline Shorthand ${ }^{\mathrm{a}}$ & Abbreviation $^{\mathrm{b}}$ & $M /(\mathrm{g} / \mathrm{mol})^{\mathrm{c}}$ & $w / \%{ }^{\mathrm{d}}$ \\
\hline $48: 0$ & PPP & 807.339 & 0.1 \\
\hline $50: 0$ & SPP & 835.393 & 0.1 \\
\hline $50: 1$ & POP & 833.377 & 1.3 \\
\hline $50: 2$ & PLP & 831.361 & 1.9 \\
\hline $50: 3$ & PLnP & 829.345 & 0.1 \\
\hline $52: 1$ & SOP & 861.431 & 0.7 \\
\hline $52: 2$ & $\mathrm{POO}$ & 859.415 & 4.9 \\
\hline $52: 3$ & PLO & 857.399 & 11.2 \\
\hline $52: 4$ & PLL & 855.383 & 8.8 \\
\hline $52: 5$ & PLnL & 853.367 & 1.2 \\
\hline $54: 1$ & SOS & 889.485 & 0.1 \\
\hline $54: 2$ & $\mathrm{SOO}$ & 887.469 & 1.2 \\
\hline $54: 3$ & $\mathrm{OOO}$ & 885.453 & 6.9 \\
\hline $54: 4$ & OLO & 883.437 & 18.8 \\
\hline $54: 5$ & OLL & 881.421 & 25.1 \\
\hline $54: 6$ & LLL & 879.405 & 14.8 \\
\hline $54: 7$ & LLnL & 877.389 & 2.6 \\
\hline \multirow[t]{2}{*}{$54: 8$} & LLnLn & 875.373 & 0.2 \\
\hline & & Overall: & 100.0 \\
\hline
\end{tabular}

${ }^{\mathrm{a}}$ The two numbers separated by a colon stand for the chain length and number of double bonds;

${ }^{\mathrm{b}}$ Abbreviation for trivial names of TAG chains: $\mathrm{P}=$ Palmitic, $\mathrm{S}=$ Stearic, $\mathrm{O}=$ Oleic, $\mathrm{L}=$ Linoleic, $\mathrm{Ln}=$ Linolenic;

'Molar mass;

${ }^{\mathrm{d}}$ Mass fraction. 

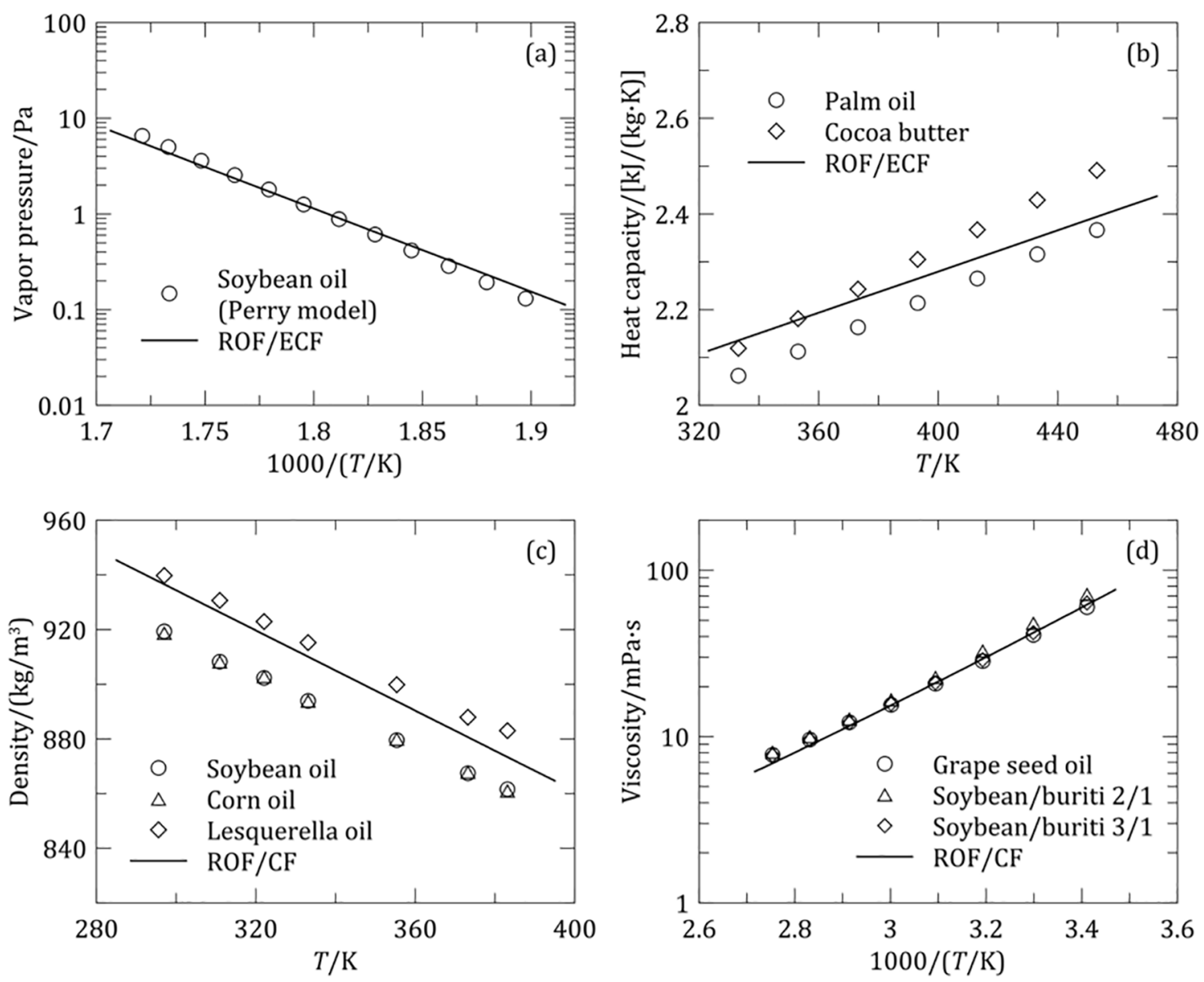

Figure 2. Thermophysical properties for some vegetable oils (experimental) and for the used ROF (predicted).

Table 3. RMSD obtained in the LLE correlation with NRTL.

\begin{tabular}{|c|c|c|}
\hline System & $T / K$ & $\Delta w / \%$ \\
\hline $\mathrm{CnO} / \mathrm{OA} / \mathrm{M}$ & 293.15 & 0.81 \\
\hline $\mathrm{CnO} / \mathrm{OA} / \mathrm{M}$ & 303.15 & 0.73 \\
\hline $\mathrm{CO} / \mathrm{OA} / \mathrm{M}$ & 303.15 & 0.98 \\
\hline $\mathrm{CO} / \mathrm{OA} / \mathrm{M}$ & 313.15 & 0.77 \\
\hline $\mathrm{SuO} / \mathrm{OA} / \mathrm{M}$ & 303.15 & 1.49 \\
\hline $\mathrm{SuO} / \mathrm{OA} / \mathrm{M}$ & 313.15 & 0.90 \\
\hline $\mathrm{JO} / \mathrm{OA} / \mathrm{M}$ & 303.1 & 0.42 \\
\hline $\mathrm{JO} / \mathrm{OA} / \mathrm{M}$ & 313.1 & 0.67 \\
\hline $\mathrm{JO} / \mathrm{OA} / \mathrm{M}$ & 323.1 & 1.03 \\
\hline $\mathrm{JO} / \mathrm{OA} / \mathrm{M}$ & 333.1 & 0.40 \\
\hline Overall & & 0.90 \\
\hline
\end{tabular}

Table 4. NRTL binary interaction parameters for ROF (1)/OA (2)/M (3) system ${ }^{\mathrm{a}, \mathrm{b}}$.

\begin{tabular}{lccccc}
\hline Pair & $A_{i j}^{(0)} / \mathrm{K}$ & $A_{i j}^{(0)} / \mathrm{K}$ & $A_{i j}^{(1)}$ & $A_{j i}^{(1)}$ & $\alpha_{i j}=\alpha_{j i}$ \\
\hline 12 & 438.71 & -4592.83 & -1.2224 & 14.495 & 0.47 \\
13 & 2619.72 & 931.84 & -9.3260 & 5.0573 & 0.2764 \\
23 & 1478.22 & -6632.54 & -6.2877 & 25.036 & 0.4408 \\
\hline
\end{tabular}

${ }^{\mathrm{a}} \mathrm{ROF}$ was represented by trilinolein (LLL) in LLE regression and in the simulation.

'NRTL model with temperature dependent parameters as $A_{i j}=A_{i j}^{(0)}+A_{i j}^{(1)} T$ 

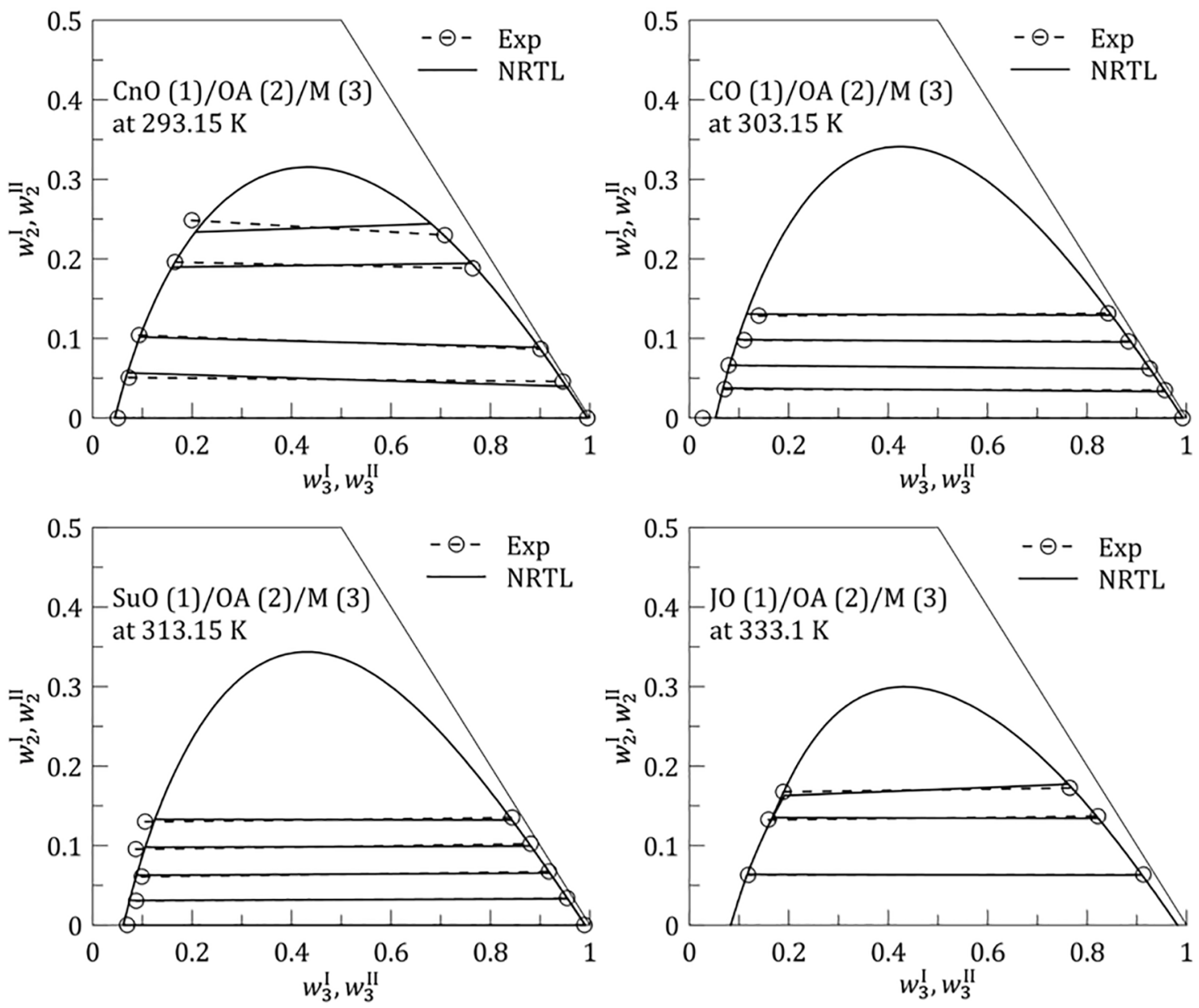

Figure 3. Experimental and calculated LLE data.

\section{Optimization of the liquid-liquid extraction process}

Table 5 shows the values of the two responses evaluated for the $2^{3}$ factorial designs, including a central point (lines 1-9 in Table 5). A test on the $w_{\mathrm{FFA}}^{\mathrm{B}}$ response showed a significant curvature, suggesting that a quadratic model may be more appropriate, for both cases 1 and 2. Therefore, extra computational experiments were carried out to complete a central composite design (CCD) (lines 10-15 in Table 5). A CCD with $\beta=1$ was used due to the impossibility of using larger $\beta$ values since $N$ is an integer variable.

The coefficients of a quadratic model were then estimated. The significance of the coefficients was evaluated using normal probability plots (Figure 4) (Bruns et al., 2006). Based on these results, the quadratic coefficient of $N$ and all the interaction coefficients did not significantly affect the $w_{\mathrm{FFA}}^{\mathrm{B}}$ response for case 1 (Figure 4a). For case 2, Figure $4 \mathrm{~b}$ shows the interaction $T \times N(1 \mathrm{~L}$ by $2 \mathrm{~L})$ and the linear coefficient of $T(T(\mathrm{~L}))$ were not significant in the range studied. For the total cost response, Figures $4 \mathrm{c}$ and $4 \mathrm{~d}$ clearly show that only the linear coefficient of $S / F[S / F(\mathrm{~L})]$ was significant.

A quadratic model for $w_{\mathrm{FFA}}^{\mathrm{B}}$ and a linear model for total cost responses were appropriately fitted. Table 6 shows the models obtained for FFD 1, the coefficient of determination $\left(R^{2}\right)$ and the residual mean square $\left(\mathrm{MS}_{\mathrm{r}}\right)$ values. The predicted results were also compared to the observed ones, as shown in Figure 5 for $w_{\mathrm{FFA}}^{\mathrm{B}}$ and total cost responses for each case. Satisfactory agreement between predicted and observed results was obtained.

Equation (3) gives a linear relationship of the response $w_{\mathrm{FFA}}^{\mathrm{B}}$ with $N$ for case 1 . Since the slope is less than zero, the maximum value for the $N$ level ( $N$ $=6$ stages) can be adopted. For case 2, although there are additional effects of $N$ according to equation (5), minimum $w_{\mathrm{FFA}}^{\mathrm{B}}$ is also obtained for $N=6$. The contour plots for $w_{\text {FFA }}^{\mathrm{B}}$, using $N=6$, are shown in Figure 6 .

As mentioned before, the optimal condition would the one that makes $w_{\mathrm{FFA}}^{\mathrm{B}}$ less than $0.5 \%$ with a minimum total cost. Minimum cost is obtained at the lowest possible $S / F$ ratio, since the total cost varies linearly with the $S / F$, according to equations (4) and (6). The lowest possible $S / F$ ratio, still satisfying $w_{\mathrm{FFA}}^{\mathrm{B}} \leq 0.5 \%$, is attained, in code units, at $\left(x_{T}, x_{N}, x_{S / F}\right)=(0.39,1.0,0.54)$ for case 1 and at $\left(x_{T}, x_{N}, x_{S / F}\right)=(0.24,1.0,0.59)$ for 
case 2 (minima of $x_{S / F}$ with respect to $x_{T}$ for $x_{N}=1$ on the $w_{\mathrm{FFA}}^{\mathrm{B}}<0.5 \%$ contour curves see Figure 6$)$. In terms of the original units, the above conditions are $(T, N, S / F)$ $=(321 \mathrm{~K}, 6$ stages, $1.27 \mathrm{~kg} / \mathrm{kg})$ and $(T, N, S / F)=(318$ $\mathrm{K}, 6$ stages, $1.30 \mathrm{~kg} / \mathrm{kg}$ ) for cases 1 and 2 , respectively.
Case 2 required a slightly higher $S / F$ than case 1 because of the higher FFA content in the feed, while a slightly higher temperature was more favorable in case 1 because of the resultant increase in solubility. The corresponding minimum costs, predicted by the models

Table 5. Values $w_{\mathrm{FFA}}^{\mathrm{B}}$ of and total cost responses obtained for FFD 1 and CCD 1 .

\begin{tabular}{|c|c|c|c|c|c|c|c|}
\hline \multirow[b]{2}{*}{ Run } & \multirow[b]{2}{*}{$T$} & \multirow[b]{2}{*}{$N^{\mathrm{a}}$} & \multirow[b]{2}{*}{$S / F$} & \multicolumn{2}{|c|}{ Case 1} & \multicolumn{2}{|c|}{ Case 2} \\
\hline & & & & $w_{\mathrm{FFA}}^{\mathrm{B}} / \%$ & Cost $/(\$ / y r)$ & $w_{\mathrm{FFA}}^{\mathrm{B}} / \%$ & Cost/(\$/yr) \\
\hline 1 & - & - & - & 7.26 & 294,743 & 13.35 & 335,828 \\
\hline 2 & + & - & - & 6.45 & 296,133 & 14.03 & 337,212 \\
\hline 3 & - & + & - & 6.73 & 299,077 & 10.72 & 340,197 \\
\hline 4 & + & + & - & 5.76 & 300,580 & 12.77 & 341,685 \\
\hline 5 & - & - & + & 3.86 & 866,390 & 5.92 & 989,597 \\
\hline 6 & + & - & + & 2.25 & 870,427 & 4.48 & 993,630 \\
\hline 7 & - & + & + & 1.85 & 872,569 & 1.84 & 995,808 \\
\hline 8 & + & + & + & 0.29 & 876,823 & 0.39 & $1,000,052$ \\
\hline 9 & 0 & 0 & 0 & 2.10 & 585,372 & 3.63 & 667,544 \\
\hline 10 & - & 0 & 0 & 4.02 & 583,343 & 5.22 & 665,507 \\
\hline 11 & 0 & - & 0 & 3.63 & 585,373 & 7.21 & 667,544 \\
\hline 12 & 0 & 0 & - & 5.87 & 298,222 & 11.57 & 339,332 \\
\hline 13 & + & 0 & 0 & 2.09 & 586,166 & 4.15 & 668,320 \\
\hline 14 & 0 & + & 0 & 1.41 & 585,372 & 2.03 & 667,544 \\
\hline 15 & 0 & 0 & + & 0.69 & 872,359 & 1.10 & 995,592 \\
\hline
\end{tabular}

${ }^{\mathrm{a}} N$ is relative to FFD 1: levels $(-),(0)$ and $(+)$ correspond to 2,4 and 6 stages, respectively.
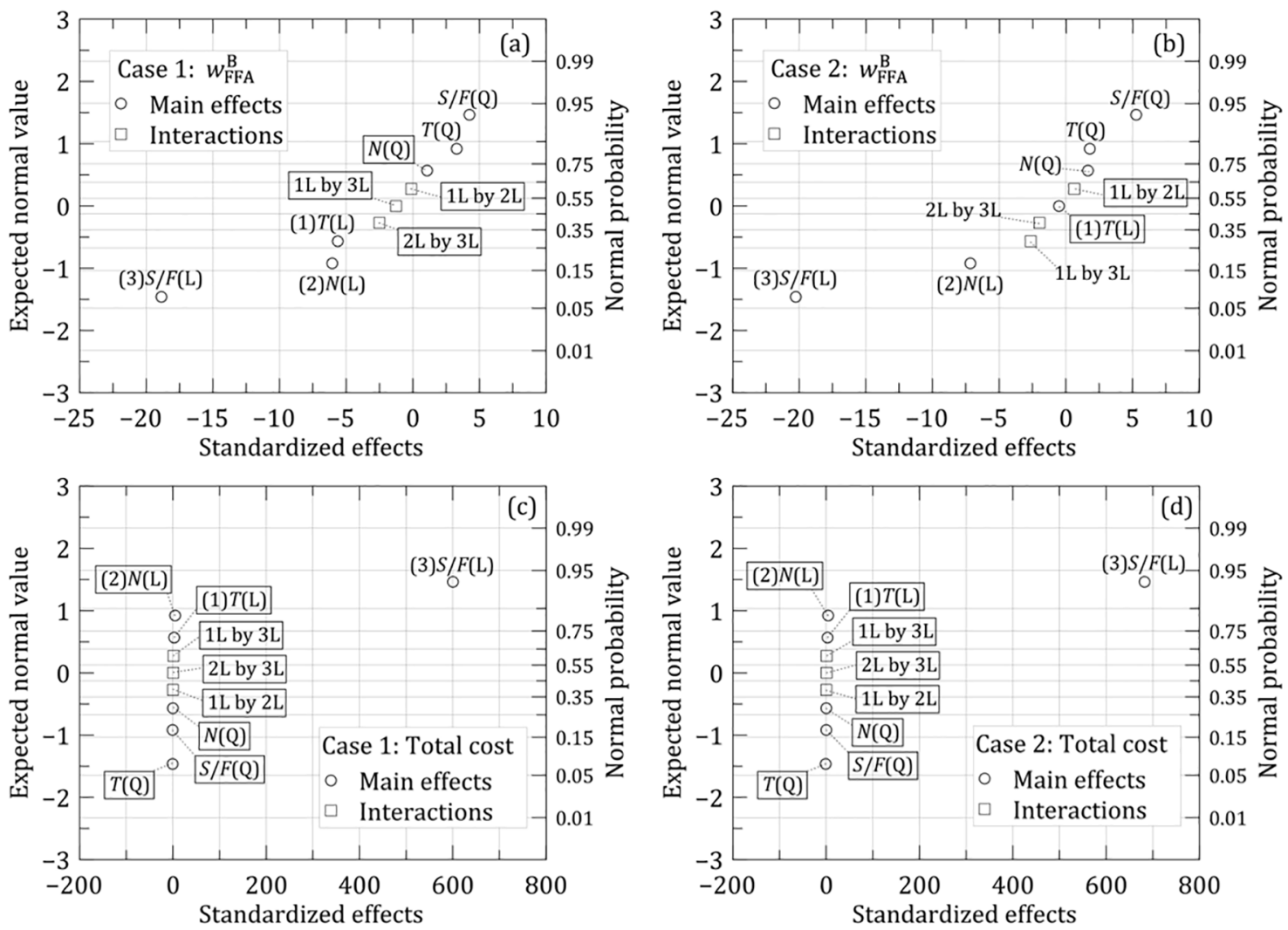

Figure 4. Normal probability plots for FFD 1 (negligible effects are enclosed in borders). 
in Table 6, were $\$ 739,833 /$ yr for case 1 and $\$ 860,571 /$ yr for case 2.

To assess if the technical benchmark $\left(w_{\mathrm{FFA}}^{\mathrm{B}} \leq 0.5 \%\right)$ could be satisfied by the rigorously modeled process, new simulations were run in Aspen under the optimal conditions predicted by the models in Table 6 . For case 1 , a mass fraction of $0.41 \%$ was obtained for $w_{\mathrm{FFA}}^{\mathrm{B}}$, thus satisfying the required specification. For case 2, however, it was necessary to increase slightly the $S / F$ ratio to 1.32 to meet the specification, resulting in $w_{\mathrm{FFA}}^{\mathrm{B}}=0.49 \%$. The corresponding costs were then calculated as $\$ 742,143 / \mathrm{yr}$ for case 1 and $\$ 899,049 / \mathrm{yr}$ for case 2 . On the basis of a ROF feed flow rate of $1050 \mathrm{~kg} / \mathrm{h}$ and a plant operation factor of $95 \%$ (8322 h per year) (Albuquerque et al., 2016), specific

Table 6. Fitted models for FFD $1^{\mathrm{a}}$.

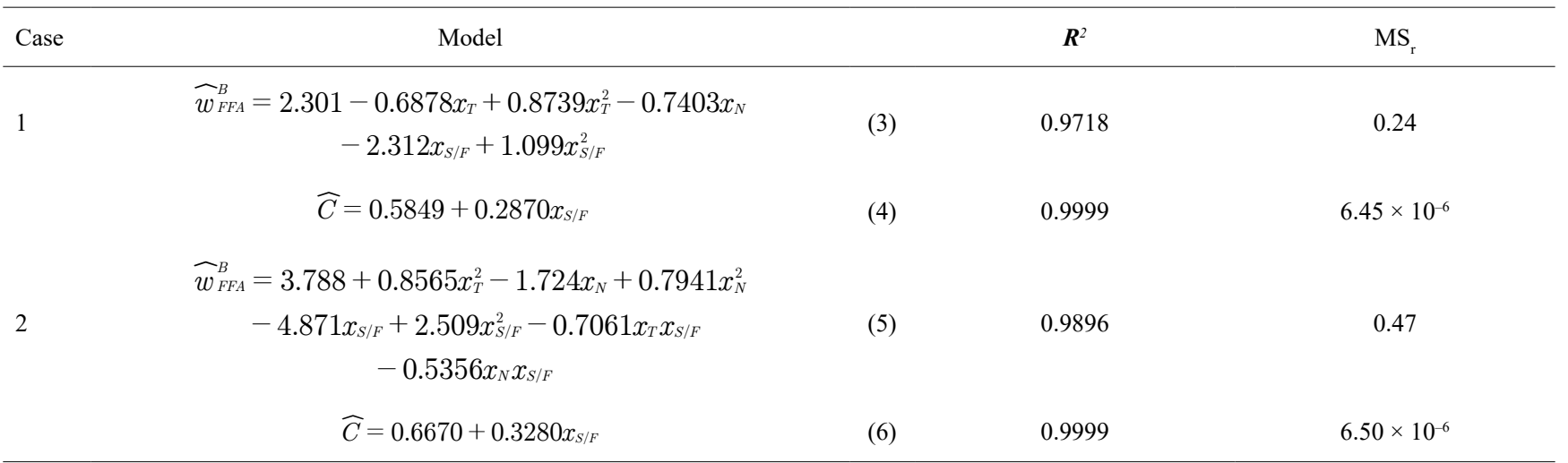

${ }^{\mathrm{a}}$ The total cost in the first year of operation $(\widehat{C})$ is given as $10^{6} \$ / \mathrm{yr}$.
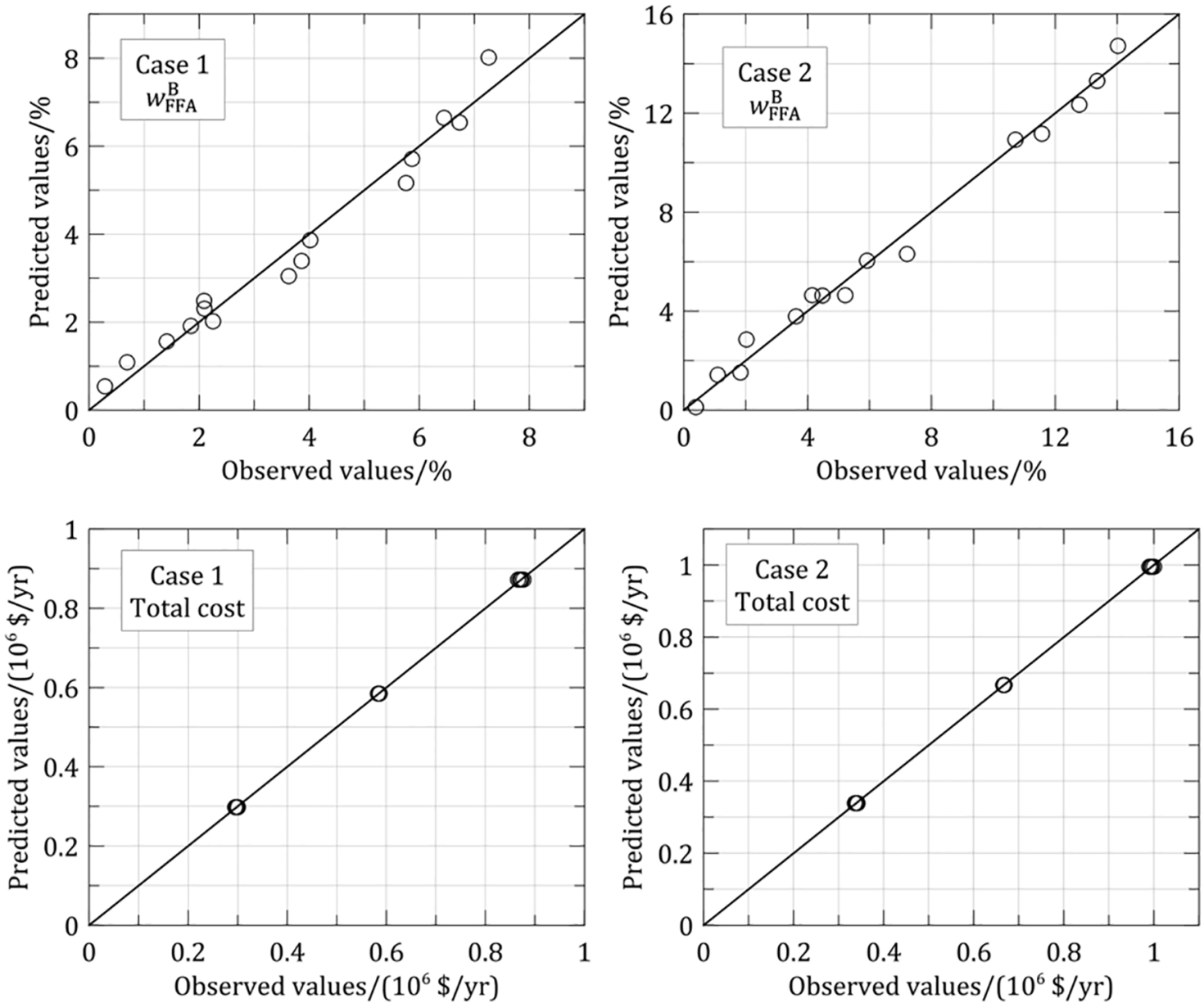

Figure 5. Observed and predicted values. 
costs (raw material cost not included) can be expressed as $\$ 84.93 /$ ton and $\$ 102.89 /$ ton for cases 1 and 2, respectively.

The optimal design and operation conditions determined above both satisfy technical $\left(w_{\mathrm{FFA}}^{\mathrm{B}} \leq\right.$ $0.5 \%$ ) and economic (minimum cost) criteria for the separation of FFA from ROF. However, for both cases 1 and 2, the optimal condition was located at $N=6$ stages. In order to investigate further if a number of stages greater than 6 could significantly shift the optimal point, a new factorial design was carried out over an extended range of $N$ while preserving the previous levels for $T$ and $S / F$, according to Table 1.

Results for the new $2^{3}$ FFD (FFD 2) are presented in Table 7 (lines 1-9, including a central point) and extra computational experiments to complete a CCD (CCD 2, lines 10-15 in Table 7). For both cases 1 and 2, the same trend obtained in the FFD 1 was observed again: only the linear effect of $S / F$ was significant for the total cost responses; and, a test on the $w_{\mathrm{FFA}}^{\mathrm{B}}$ responses showed significant curvatures, suggesting again quadratic models. However, contrary to FFD 1 , the number of stages did not affect the $w_{\text {FFA }}^{\mathrm{B}}$ response significantly, for both cases 1 and 2, as shown in Figure 7 and in Table 8, thus, indicating that $N=6$ stages, as discussed above, is acceptable as the optimal condition. This conclusion is in agreement with Albuquerque et al. (2016) who observed that $w_{\mathrm{FFA}}^{\mathrm{B}}$ is not considerably affected by increasing the number of stages above five.

As mentioned before, similar studies using methanol as the solvent were not found in the literature. There are, however, extraction studies using ethanol and ethanol/water mixtures as solvents for the refining of edible oils with considerably lower FFA concentrations (Pina and Meirelles, 2000; Batista et al., 2002).
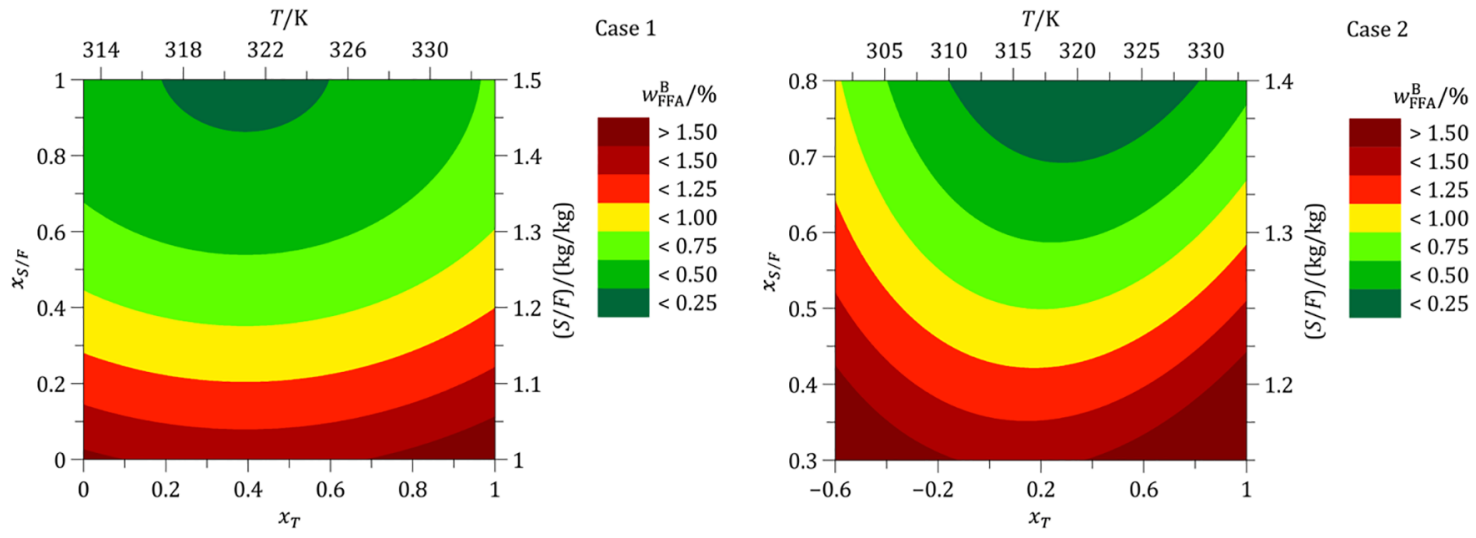

Figure 6. Contour plots for $w_{\mathrm{FFA}}^{\mathrm{B}}$ at $N=6$ stages $\left(x_{N}=1\right)$.

Table 7. Values of $\underset{w \mathrm{FFA}}{\mathrm{B}}$ and total cost responses obtained from FFD 2 and CCD 2.

\begin{tabular}{|c|c|c|c|c|c|c|c|}
\hline \multirow[b]{2}{*}{ Run } & \multirow[b]{2}{*}{$T$} & \multirow[b]{2}{*}{$N^{\mathrm{a}}$} & \multirow[b]{2}{*}{$S / F$} & \multicolumn{2}{|c|}{ Case 1} & \multicolumn{2}{|c|}{ Case 2} \\
\hline & & & & $w_{\mathrm{FFA}}^{\mathrm{B}} / \%$ & Cost/(\$/yr) & $w_{\mathrm{FFA}}^{\mathrm{B}} / \%$ & $\operatorname{Cost} /(\$ / y r)$ \\
\hline 1 & - & - & - & 6.73 & 299,077 & 10.72 & 340,197 \\
\hline 2 & + & - & - & 5.76 & 300,580 & 12.77 & 341,685 \\
\hline 3 & - & + & - & 6.68 & 302,930 & 10.05 & 344,083 \\
\hline 4 & + & + & - & 5.74 & 304,536 & 12.56 & 345,662 \\
\hline 5 & - & - & + & 1.85 & 872,569 & 1.84 & 995,808 \\
\hline 6 & + & - & + & 0.29 & 876,823 & 0.39 & $1,000,052$ \\
\hline 7 & - & + & + & 1.33 & 878,063 & 1.05 & $1,001,331$ \\
\hline 8 & + & + & + & 0.05 & 882,511 & 0.04 & $1,005,763$ \\
\hline 9 & 0 & 0 & 0 & 1.01 & 587,815 & 1.20 & 669,999 \\
\hline 10 & - & 0 & 0 & 3.32 & 588,289 & 3.28 & 670,486 \\
\hline 11 & 0 & - & 0 & 1.41 & 585,372 & 2.03 & 667,544 \\
\hline 12 & 0 & 0 & - & 5.72 & 300,213 & 10.80 & 341,336 \\
\hline 13 & + & 0 & 0 & 1.06 & 591,270 & 1.68 & 673,448 \\
\hline 14 & 0 & + & 0 & 0.75 & 590,160 & 0.71 & 672,357 \\
\hline 15 & 0 & 0 & + & 0.08 & 875,209 & 0.07 & 998,454 \\
\hline
\end{tabular}

${ }^{\mathrm{a}} \mathrm{N}$ is relative to FFD 2: levels (-), (0) and (+) correspond to 6, 8 and 10 stages, respectively. 
Table 8. Fitted models for FFD $2^{\mathrm{a}}$.

\begin{tabular}{|c|c|c|c|c|}
\hline Case & Model & & $\boldsymbol{R}^{2}$ & $\mathrm{MS}_{\mathrm{r}}$ \\
\hline 1 & $\begin{array}{c}\widehat{w}_{F F A}^{B}=1.167-0.7032 x_{T}+0.8602 x_{T}^{2}-2.702 x_{S / F} \\
+1.567 x_{S / F}^{2}\end{array}$ & (7) & 0.9878 & 0.11 \\
\hline \multirow{3}{*}{2} & $\widehat{C}=0.5890+0.2878 x_{S / F}$ & $(8)$ & 0.9999 & $7.40 \times 10^{-6}$ \\
\hline & $\begin{aligned} \widehat{w}_{F F A}^{B}=1.410+ & 0.9235 x_{T}^{2}-5.352 x_{S / F}+3.881 x_{S / F}^{2} \\
& -0.8803 x_{T} x_{S / F}\end{aligned}$ & (9) & 0.9903 & 0.35 \\
\hline & $\widehat{C}=0.6712+0.3288 x_{S / F}$ & (10) & 0.9999 & $7.43 \times 10^{-6}$ \\
\hline
\end{tabular}

${ }^{a}$ The total cost in the first year of operation $(\widehat{C})$ is given as $10^{6} \$ / y r$.
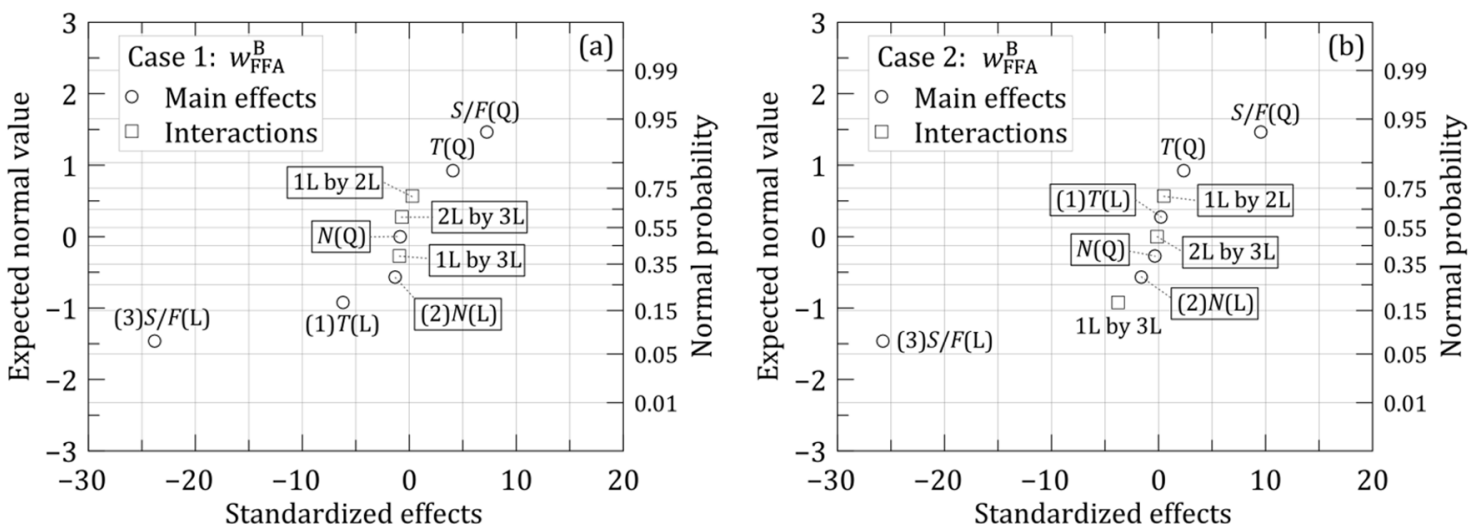

Figure 7. Normal probability plots for FFD 2 (negligible effects are enclosed in borders).

Although these authors demonstrated that it was possible to attain $w_{\mathrm{FFA}}^{\mathrm{B}} \leq 0.5 \%$, in general, this required a higher number of stages with $S / F$ ratios varying from 1.27 to 2. According to Mohsen-Nia and Khodayari (2008), methanol presents selectivities from 2.5 to 4 times higher than ethanol for oleic acid extraction from sunflower oil. In addition, the higher the water concentration, the more difficult the FFA separation becomes (Batista et al., 2002; Rodrigues et al., 2007). As a result, methanol presented better extraction properties than ethanol and ethanol/water mixtures requiring fewer stages and lower $S / F$ ratios.

\section{CONCLUSIONS}

The technical and economic feasibility of the separation of FFA from a ROF using LLEx with methanol as the solvent was investigated using RSM for two cases of typical FFA contents found in yellow and brown greases. All variables studied $(T, N$ and $S / F$ ) showed significant effects on the $w_{\mathrm{FFA}}^{\mathrm{B}}$ response. On the other hand, for both cases, the total cost response was only significantly affected by the linear effect of the $S / F$ ratio. As a result, a trade-off between
$w_{\mathrm{FFA}}^{\mathrm{B}} \leq 0.5 \%$ and minimum total cost in the first year of operation was adopted to obtain the optimal condition, since an increase in the $S / F$ entails a decrease in the $w_{\text {FFA }}^{\mathrm{B}}$ value while increasing the total cost. Therefore, optimal design and operation conditions were $T=321$ $\mathrm{K}, N=6$ stages and $S / F=1.27$ for case 1 ; and $T=$ $318 \mathrm{~K}, N=6$ stages and $S / F=1.32$ for case 2 . Under these conditions, process simulation indicated that the technical specification can be satisfied, resulting in a $w_{\mathrm{FFA}}^{\mathrm{B}}$ value of $0.41 \%$ for case 1 and $0.49 \%$ for case 2 . The associated costs were $\$ 742,143 / \mathrm{yr}$ for case 1 and $\$ 899,049 / \mathrm{yr}$ for case 2 . The corresponding specific costs for a ROF feed flow rate of $1050 \mathrm{~kg} / \mathrm{h}$ and a plant operation factor of $95 \%$ ( $8322 \mathrm{~h}$ per year) were $\$ 84.93$ / ton and $\$ 102.89 /$ ton for cases 1 and 2, respectively. The above minimum costs do not include raw material (ROF) costs as already pointed out.

\section{ACKNOWLEDGMENTS}

The authors acknowledge FACEPE/NUQAAPE, INCTAA, CNPQ and FINEP for financial support. A. A. A. is also grateful to Capes for a Ph.D. scholarship. 


\section{NOMENCLATURE}

$A_{i j}$ - NRTL binary interaction parameter (K)

$A_{i j}^{(0)}$ - Coefficient in the NRTL binary interaction parameter equation $(\mathrm{K})$

$A_{i j}^{(1)}$ - Coefficient in the NRTL binary interaction parameter equation

$C$ - Total cost in the first year of operation $\left(10^{6} \$ / \mathrm{yr}\right)$

$F$ - Objective function (see equation 1 )

$M$ - Molar mass (g/mol)

$\mathrm{MS}_{\mathrm{r}}$ - Residual mean square

$N$ - Number of stages

$N_{\mathrm{c}}$ - Number of components

$N_{\text {D }}$ - Number of data sets

$N_{\mathrm{t}}$ - Number of tie lines

$R^{2}$ - Coefficient of determination

$S / F$ - Solvent to feed mass ratio

$T$ - Temperature (K)

$w$ - Mass fraction (\%)

$w_{\mathrm{FFA}}^{\mathrm{B}}-$ FFA mass fraction (solvent free) in the oil-

rich output bottom stream of the extraction column

$(\%)$

$x_{N}$ - Number of stages value (coded value)

$x_{S / F}$ - Solvent to feed mass ratio value (coded value)

$x_{T}$ - Temperature value (coded value)

\section{Greek Symbols}

$\alpha_{i j}$ - NRTL non-randomness parameter

$\beta$ - Distance of each axial point (also called star point) from the center

\section{Subscripts}

FFA - Free fatty acid

$i-i$-th component

$j-j$-th experimental LLE tie line

$k$ - $k$-th data set

$N$ - Number of stages

$S / F$ - Solvent to feed mass ratio

$T$ - Temperature

\section{Superscripts}

B - Bottom output stream of the extraction column

cal - Calculated

exp - Experimental

I,II - Liquid phases in equilibrium

$l$ - $l$-th phase

\section{Abbreviations}

CCD - central composite design

CEPCI - Chemical Engineering's Plant Cost Index

$\mathrm{CF}$ - Constituent Fragments

$\mathrm{CnO}$ - canola oil
$\mathrm{CO}$ - corn oil

ECF - Extended Constituent Fragments

FFA - free fatty acid

FFD - full factorial design

JO - jatropha curcas oil

$\mathrm{L}$ - linoleic

Ln - linolenic

LLE - liquid-liquid equilibrium

LLEx - liquid-liquid extraction

LLL - trilinolein

$\mathrm{M}$ - methanol

NRTL - Non-Random Two-Liquid

$\mathrm{O}$ - oleic

$\mathrm{OA}$ - oleic acid

$\mathrm{P}$ - palmitic

RDC - rotating disk contactor

RMSD - root mean square deviation

ROF - residual oil and fat

RSM - response surface methodology

$\mathrm{S}$ - stearic

$\mathrm{SuO}$ - sunflower oil

TAG - triacylglycerol

\section{REFERENCES}

Adewale, P., Dumont, M.-J. and Ngadi, M., Recent trends of biodiesel production from animal fat wastes and associated production techniques, Renew. Sust. Energ. Rev., 45 574-588 (2015).

Albuquerque, A.A., Danielski, L. and Stragevitch, L., Techno-economic assessment of an alternative process for biodiesel production from feedstock containing high levels of free fatty acids, Energy \& Fuels, 30 (11) 9409-9418 (2016).

Antoniosi Filho, N.R., Mendes, O.L. and Lanças, F. M, Computer Prediction of Triacylglycerol Composition of Vegetable Oils by HRGC, Chromatographia, 40 557-562 (1995).

Avhad, M.R. and Marchetti, J.M., A review on recent advancement in catalytic materials for biodiesel production, Renew. Sust. Energ. Rev., 50 696-718 (2015).

Batista, E., Monnerat, S., Kato, K., Stragevitch, L. and Meirelles, A.J., Liquid-liquid equilibrium for systems of canola oil, oleic acid, and short-chain alcohols, J. Chem. Eng. Data, 44, No. 6, 1360-1364 (1999a).

Batista, E., Wolf Maciel, M.R. and Meirelles, A.J.A., Simulation of the Deacidification of Vegetable Oil by Liquid-Liquid Extraction. Proceedings of the 2nd Conference on Process Integration, Modelling 
and Optimisation for Energy Saving and Pollution Reduction. Budapest, Hungary (1999b).

Batista, E., Antoniassi, R., Wolf Maciel, M.R. and Meirelles, A.J.A., Liquid-liquid extraction for deacidification of vegetable oils. Proceeding of International Solvent Extraction Conference. South Africa (2002).

Bhosle, B. and Subramanian, R., New approaches in deacidification of edible oils--a review, J. Food Eng., 69, No. 4 481-494 (2005).

Bruns, R.E., Scarminio, I.S. and de Barros Neto, B., Statistical Design - Chemometrics. Elsevier, Campinas (2006).

Cai, Z.-Z., Wang, Y., Teng, Y.-L., Chong, K.-M., Wang, J.-W., Zhang, J.-W. and Yang, D.-P., A two-step biodiesel production process from waste cooking oil via recycling crude glycerol esterification

catalyzed by alkali catalyst, Fuel Process. Technol., 137 186-193 (2015).

Canakci, M. and Sanli, H., Biodiesel production from various feedstocks and their effects on the fuel properties, J. Ind. Microbiol. Biot., 35, No. 5 431441 (2008).

Canakci, M. and Van Gerpen, J., Biodiesel production from oils and fats with high free fatty acids, Transactions of the ASAE, 44, No. 6, 1429 (2001).

Ceriani, R., Paiva, F.R., Goncalves, C.B., Batista, E.A. and Meirelles, A.J., Densities and viscosities of vegetable oils of nutritional value, J. Chem. Eng. Data, 53, No. 8 1846-1853 (2008).

Cruz-Forero, D.-C., González-Ruiz, O.-A. and LópezGiraldo, L.-J., Calculation of thermophysical properties of oils and triacylglycerols using an extended constituent fragments approach, Ciencia, Tecnología y Futuro, 5, No. 1 67-82 (2012).

Gnanaprakasam, A., Sivakumar, V.M., Surendhar, A., Thirumarimurugan, M. and Kannadasan, T., Recent strategy of biodiesel production from waste cooking oil and process influencing parameters: a review, J. Energy, 2013, (2013).

Iasmin, M., Dean, L.O., Lappi, S.E. and Ducoste, J.J., Factors that influence properties of FOG deposits and their formation in sewer collection systems, Water Res., 49 92-102 (2014).

Jorge, N., Soares, B.B.P., Lunardi, V.M. and Malacrida, C.R., Physico-chemical alterations of sunflower, corn and soybean oils in deep fat frying (in portuguese), Quim. Nova, 28, No. 6, 947 (2005).

Liu, Y., Lu, H., Liu, C. and Liang, B., Solubility Measurement for the Reaction Systems in PreEsterification of High Acid Value Jatropha curcas L. Oil, J. Chem. Eng. Data, 54, No. 5 1421-1425 (2008).
Ma, F. and Hanna, M.A., Biodiesel production: a review, Bioresour. Technol., 70, No. 1 1-15 (1999).

Mohite, S., Kumar, S., Pal, A. and Maji, S., Biodiesel Production from High Free Fatty Acid Feed Stocks through Transesterification. International Conference of Advance Research and Innovation (ICARI). New Delhi (2015).

Mohsen-Nia, M. and Dargahi, M., Liquid-liquid equilibrium for systems of (corn oil+ oleic acid+ methanol or ethanol) at (303.15 and 313.15) K, J. Chem. Eng. Data, 52, No. 3 910-914 (2007).

Mohsen-Nia, M. and Khodayari, A., De-acidification of sunflower oil by solvent extraction:(Liquid+ liquid) equilibrium data at $\mathrm{T}=(303.15$ and 313.15$) \mathrm{K}, \mathrm{J}$. Chem. Thermodyn., 40, No. 8 1325-1329 (2008).

Morad, N.A., Kamal, A.M., Panau, F. and Yew, T., Liquid specific heat capacity estimation for fatty acids, triacylglycerols, and vegetable oils based on their fatty acid composition, J. Am. Oil Chem. Soc., 77, No. 9 1001-1006 (2000).

Noureddini, H., Teoh, B. and Clements, L.D., Densities of vegetable oils and fatty acids, J. Am. Oil Chem. Soc., 69, No. 12 1184-1188 (1992).

Ortner, M.E., Müller, W., Schneider, I. and Bockreis, A., Environmental assessment of three different utilization paths of waste cooking oil from households, Resour. Conserv. Recy., 106 59-67 (2016).

Perry, E., Weber, W. and Daubert, B., Vapor pressures of phlegmatic liquids. I. Simple and mixed triglycerides, J. Am. Chem. Soc., 71, No. 11 3720-3726 (1949).

Pina, C.G. and Meirelles, A.J., Deacidification of corn oil by solvent extraction in a perforated rotating disc column, J. Am. Oil Chem. Soc., 77 553-559 (2000).

Refaat, A., Different techniques for the production of biodiesel from waste vegetable oil, Int. J. Environ. Sci. Tech., 7, No. 1 183-213 (2010).

Renon, H. and Prausnitz, J.M., Local compositions in thermodynamic excess functions for liquid mixtures, Aiche J., 14, No. 1 135-144 (1968).

Rodrigues, C.E., Gonçalves, C.B., Batista, E. and Meirelles, A.J., Deacidification of vegetable oils by solvent extraction, Recent Pat. Eng., 1, No. $195-$ 102 (2007).

Seader, J.D., Henley, E.J. and Roper, D.K., Separation process principles: chemical and biochemical operations. John Wiley \& Sons, USA (2011).

Seider, W.D., Seader, J.D. and Lewin, D.R., Product \& Process Design Principles: Synthesis, Analysis and Evaluation. John Wiley \& Sons, USA (2009). 
Stragevitch, L. and d'Avila, S., Application of a generalized maximum likelihood method in the reduction of multicomponent liquid-liquid equilibrium data, Braz. J. Chem. Eng., 14, (1997).

Tsoutsos, T.D., Tournaki, S., Paraíba, O. and Kaminaris, S.D., The Used Cooking Oil-tobiodiesel chain in Europe assessment of best practices and environmental performance, Renew. Sust. Energ. Rev., 54 74-83 (2016).

Vaisali, C., Charanyaa, S., Belur, P.D. and Regupathi, I., Refining of edible oils: a critical appraisal of current and potential technologies, Int. J. Food Sci. Tech., 50, No. 1 13-23 (2015).

Van Gerpen, J., Biodiesel processing and production, Fuel Process. Technol., 86, No. 10 1097-1107 (2005).

Zhang, Y., Dube, M., McLean, D. and Kates, M., Biodiesel production from waste cooking oil: 1 . Process design and technological assessment, Bioresour. Technol., 89, No. 1 1-16 (2003).

Zong, L., Ramanathan, S. and Chen, C.-C., Fragmentbased approach for estimating thermophysical properties of fats and vegetable oils for modeling biodiesel production processes, Ind. Eng. Chem. Res., 49, No. 2 876-886 (2009). 
